\title{
SIMULATIVE INVESTIGATION OF TRANSMISSION PERFORMANCE FOR PROPOSED NG-PON 2 BASED ON DPQSK MODULATED DOWNSTREAM WITH TWO DIFFERENT INTENSITY MODULATED UPSTREAMS
}

\author{
Areez Khalil Memon \\ FEST, Indus University, Karachi, (Pakistan) \\ E-mail: areez.memon@indus.edu.pk
}

Ahmed Muddassir Khan

FEST, Indus University, Karachi, (Pakistan)

E-mail: ahmed.muddassir@indus.edu.pk

Syed Hyder Abbas Musavi

FEST, Indus University, Karachi, (Pakistan)

E-mail: Dean@indus.edu.pk

Faizan ur Rehman

FEST, Indus University, Karachi, (Pakistan)

E-mail: faizan.rehman@indus.edu.pk

Atif Mehmood

FEST, Indus University, Karachi, (Pakistan)

E-mail: atifmehmood@indus.edu.pk

Sajid Hussain

FEST, Indus University, Karachi, (Pakistan) E-mail: sajidhussain@indus.edu.pk 


\section{ABSTRACT}

We present a comparison between the two high data rate next generation passive optical network (NG-PON 2) which are feasible to fulfill the future demand for bandwidth hungry applications that exceeds beyond 10Gbps. This paper summarizes the best suitable network for future bandwidth hungry applications by simulating both networks through optisys simulated software considering standard values and recommendations for NG-PON 2. Both networks support 40Gbps with Differential Quadrature Phase Shift Keying (DQPSK) while at upstream one network supports 10Gbps with On Off Keying (OOK) and other support Inverted return to zero (IRZ) with $10 \mathrm{Km}$ fiber span. Comparison of both networks transmission performance in terms of BER with Rx power and OSNR has been investigated and results shows that NG-PON 2 support 40Gbps with DQPSK and 10Gbps IRZ is quite better than other network with higher sensitivity and OSNR.

\section{KEYWORDS}

Differential Quadrature Phase Shift Keying (DQPSK), ON-OFF Keying (OOK), Inverted Return to Zero (IRZ), Next Generation Passive Optical Network-2 (NGPON-2), Bit Error Rate (BER), Optical Signal to Noise Ratio (OSNR).

\section{INTRODUCTION}

Evolution in PON is essential to deal with future bandwidth hungry applications. Existing PON have a capability to transmit 10Gbps and $1 \mathrm{Gpbs}$ downstream and upstream data rate with HDTV, multimedia and video calling simultaneously [1-2]. As per the survey of CISCO in 2016 it is predicted that data rate will be increased twice compare to 2015 data rate [3]. It is necessary to increase the data rate capability up to 40Gpbs in PON to deal with future bandwidth hungry applications and named as NG-PON 2 [4-6].

For higher data rate in PON, different modulation formats have been investigated and analyzed in order to have less nonlinearities and dispersion effects [7]. Different modulation formats have been implemented in 10Gbps data rate such as NRZ, RZ, MDRZ [8], CSRZ, MDRZ, DPSK [9], RZ-DQPSK with OOK [10], Differential Phase Shift Keying (DPSK) with OOK [11], Carrier suppressed return to zero CSRZ-DQPSK with OOK [10-12], NRZ-DQPSK with ASK [13,14], DPSK with IRZ [15,16]. For high data rate, few modulation techniques have been proposed and analyzed such as DQPSK with IRZ [17] and DQPSK with OOK [18].

In this paper we have analyzed the performance of two high data rate NG-PON 2 having the same downstream modulation DQPSK but different upstream modulation OOK and IRZ. DQPSK modulation format is used as it has high spectrum efficiency and high transmission impairments [19] and OOK and IRZ modulation formats used as they are simple and cost effective design [20,21]. Both DQPSK with OOK and DQPSK with IRZ architectures have $40 \mathrm{Gbps}$ data rate in downstream and $10 \mathrm{Gpbs}$ data rate in upstream with $10 \mathrm{~km}$ fiber span by using FBG dispersion compensation.

\section{DESCRIPTION OF SIMULATION}

For analyzing the performance of both architectures, simulation software has been used named as Optisystem [22]. Figure 1 and Figure 2 shows the simulated model of high data rate DQPSK with OOK and high data rate DQPSK with IRZ NG-PON 2 having same parameters except different modulation technique in upstream. Both networks have 
OLT, ONU and optical fiber length of $10 \mathrm{Km}$ with FBG dispersion compensator. CW LASER at $0 \mathrm{dBm}$ launch power is used as a carrier source which is modulated with electrical data stream generated from pseudo random generator (PRBS) having data rate 40Gbps through two series connected Lithium Niobate Mach-Zehnder modulator (LiNb MZM). Modulated signal is transmitted through optical fiber span of $10 \mathrm{~km}$ with

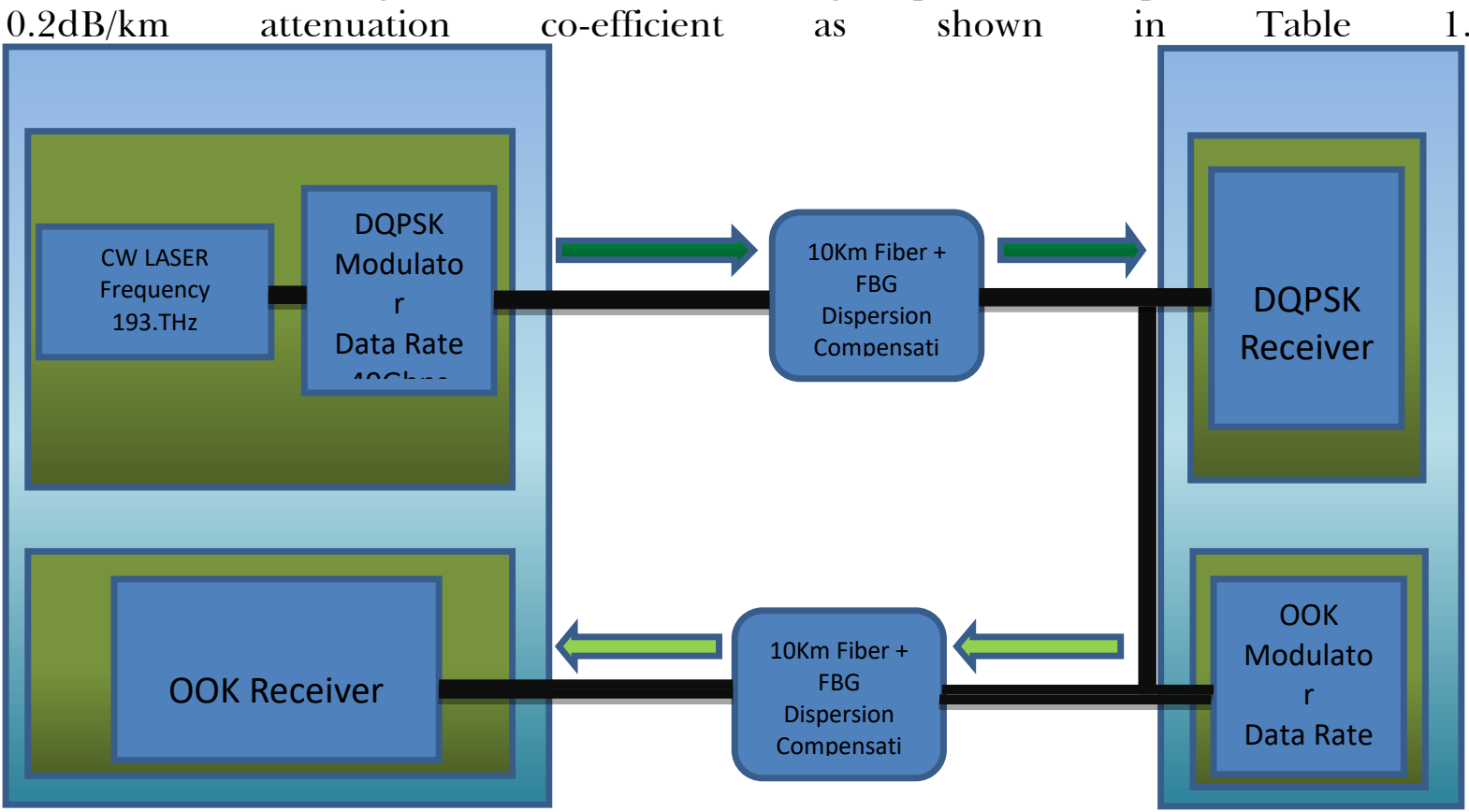

Figure 1. 40Gbps DQPSK with OOK Next Generation Passive Optical Network (NG-PON).

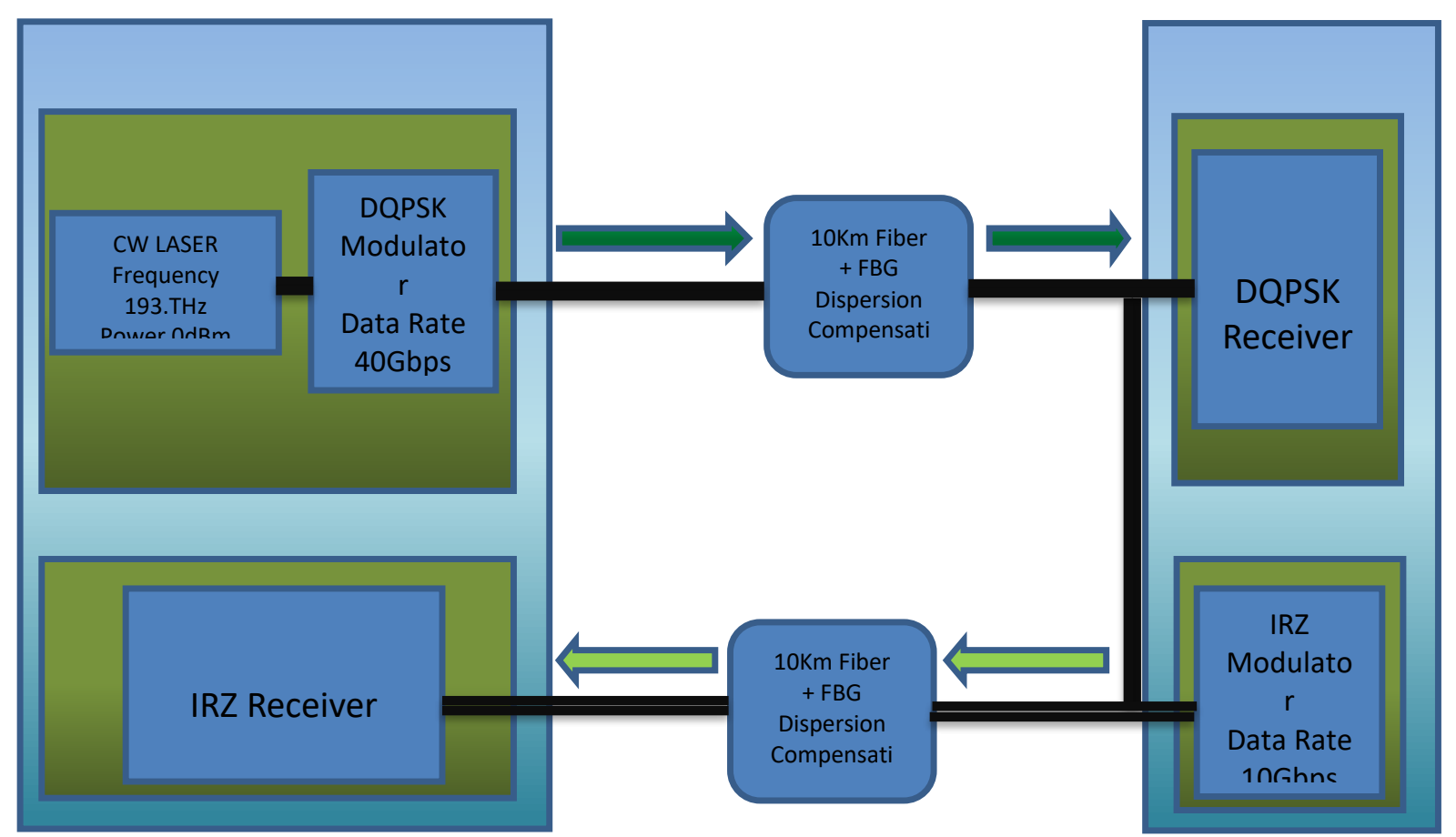

Figure 2. 40Gbps DQPSK with IRZ Next Generation Passive Optical Network (NG-PON) with FBG. 
Table 1. Simulated Model Parameters for both Networks.

\begin{tabular}{|c|c|c|}
\hline \multirow{2}{*}{ Transmission Section } & Parameter & Values \\
\hline \multirow{4}{*}{ Fiber } & Power of Laser & $0 \mathrm{dBm}$ \\
\cline { 2 - 3 } & Frequency of Laser & $193.1 \mathrm{THz}$ \\
\cline { 2 - 3 } & Fiber Length & $10 \mathrm{Km}$ \\
\cline { 2 - 3 } & Dispersion slop & $0.075 \mathrm{ps} / \mathrm{nm}^{2} / \mathrm{km}^{2}$ \\
\cline { 2 - 3 } & Eon Linear index-coefficient & $2.6 \times 10^{-20}$ \\
\cline { 2 - 3 } & Attenuation Coeff: & $0.2 \mathrm{~dB} / \mathrm{km}$ \\
\cline { 2 - 3 } & Dispersion & $16.75 \mathrm{ps} / \mathrm{nm} / \mathrm{km}$ \\
\hline Receiver Section & Filter Cutoff Frequency & $0.75 * \mathrm{bit} \mathrm{rate} \mathrm{Hz}$ \\
\hline
\end{tabular}

DQPSK modulation technique is used in the downstream of both networks. DQPSK transmitter modulator is shown in Figure 3. DQPSK transmitter is composed of CW Laser having $0 \mathrm{dBm}$ power $(1 \mathrm{~mW})$ works at $1550 \mathrm{~nm}$ and data is generated from psuedorandom bit squence (PRBS) generator of 40Gbps. Data is modulated after differential precoding through two LiNb Mach-Zehnder Modulators. One modulator is act as a phase modulator to create a dephasing of $\pi / 2$.

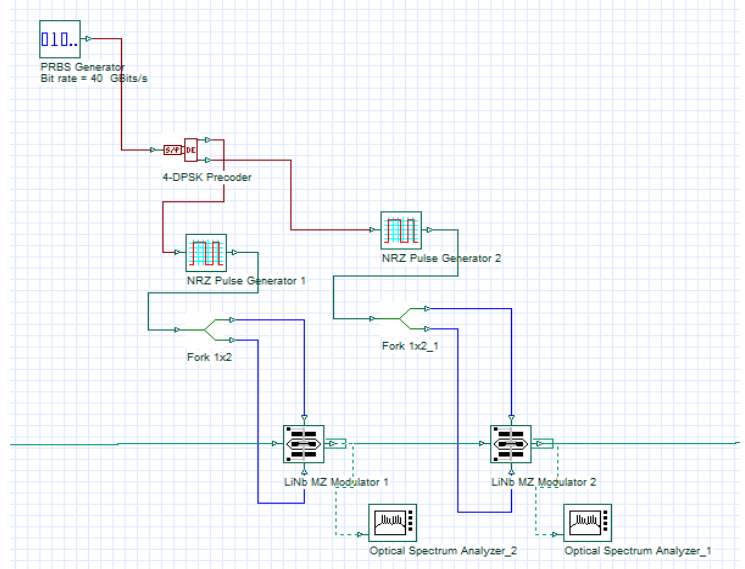

Figure 3. DQPSK Transmitter.

After modulation, signal is transmitted through optical fiber towards the reciever of the ONU where signal is splitted into two signals demodulated through coupler and followed by two photodetector PIN. There output combines with the subtractor and gives the electrical output as shown in Figure 4.

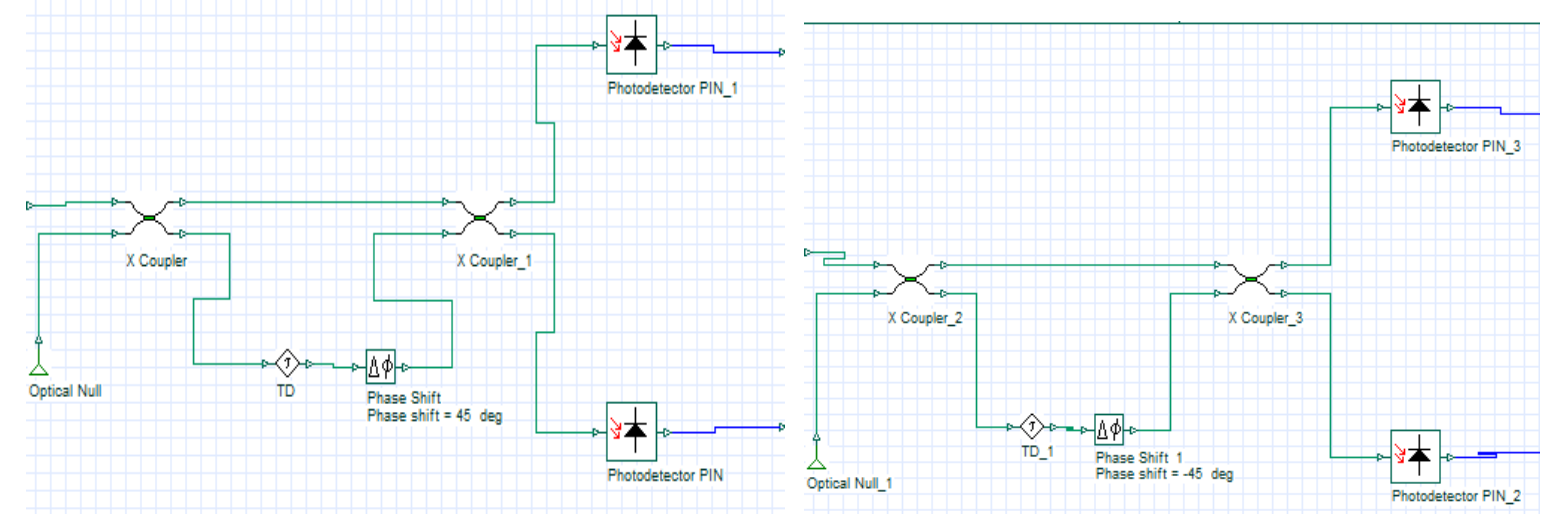

Figure 4. DQPSK Receiver for Inphase and Quadrature phase Signal. 
The ONU transmitter remodulates the signal through OOK modulation in one network while IRZ in another network. For OOK transmitter, same signal is modulated through Mach-Zehnder modulator with data generator from psuedo-random bit squence (PRBS) generator of 10Gbps shown in Figure 5.

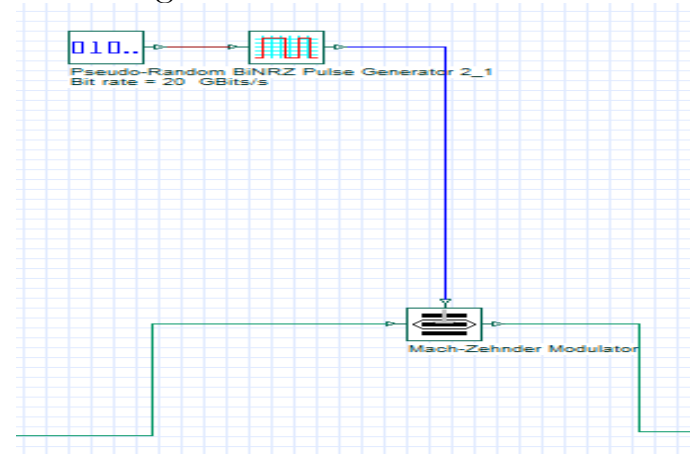

Figure 5. OOK Transmitter.

Modulated signal transmitted through optical fiber received by photodetector which demodulates the signal gives electrical output as shown in Figure 6.

Figure 6. OOK Receiver.

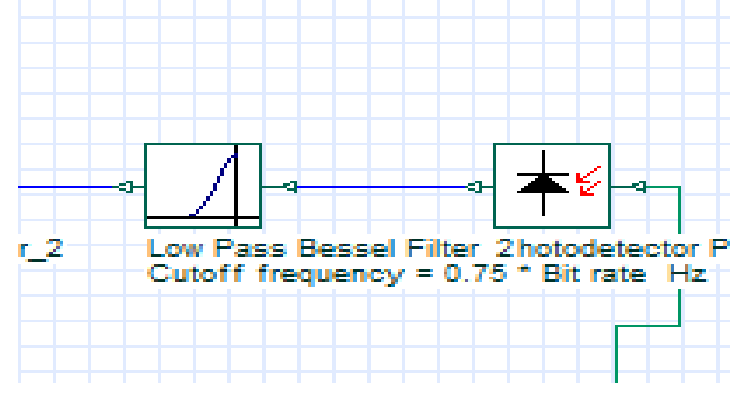

Whereas IRZ transmitter for second network, same signal is modulated through MachZehnder modulator with data generator from psuedo-random bit squence (PRBS) generator of $10 \mathrm{Gbps}$ which added with pulse generator having frequency $5 \mathrm{GHz}$ and phase of $-\pi / 4$ shown in Figure 7.

Figure 7. IRZ Transmitter.

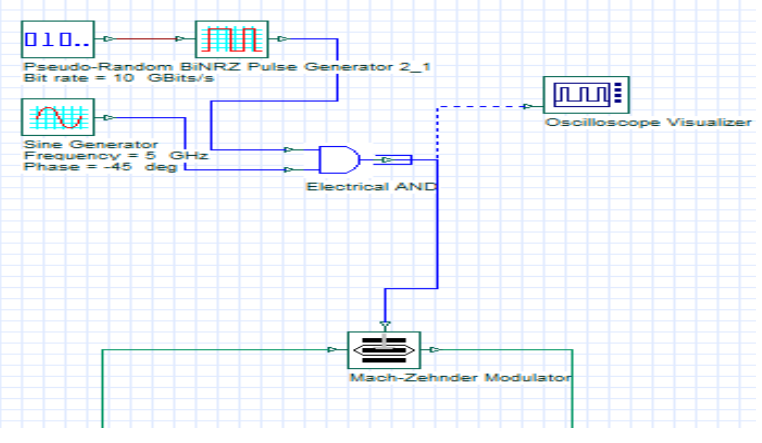

Modulated signal transmitted through optical fiber received by photodetector which demodulates the signal gives electrical output shown in Figure 8.

Figure 8. IRZ Receiver.

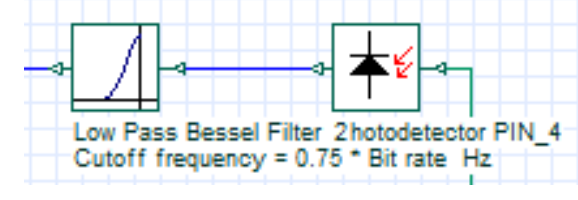




\section{DISCUSSION OF RESULTS}

Figure 9,10,11 and 12 shows the optical spectrum of downstream and upstream of both DQPSK with OOK and DQPSK with IRZ at a carrier frequency of $193.1 \mathrm{THz}(1550 \mathrm{~mm}$ Wavelength).

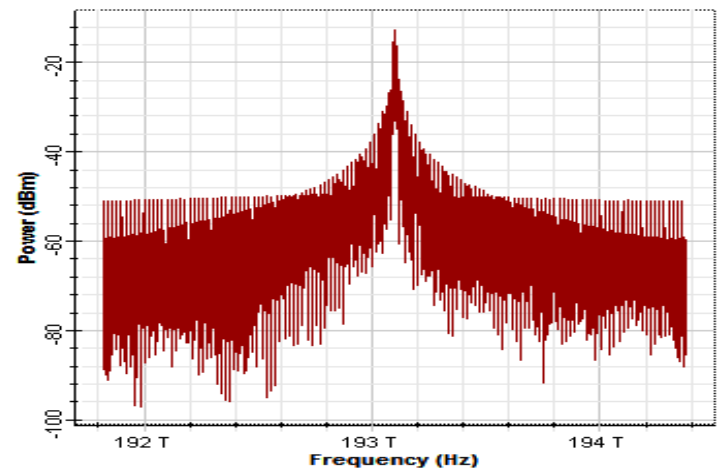

Figure 9. Optical Spectruem of Downstream DQPSK with OOK.

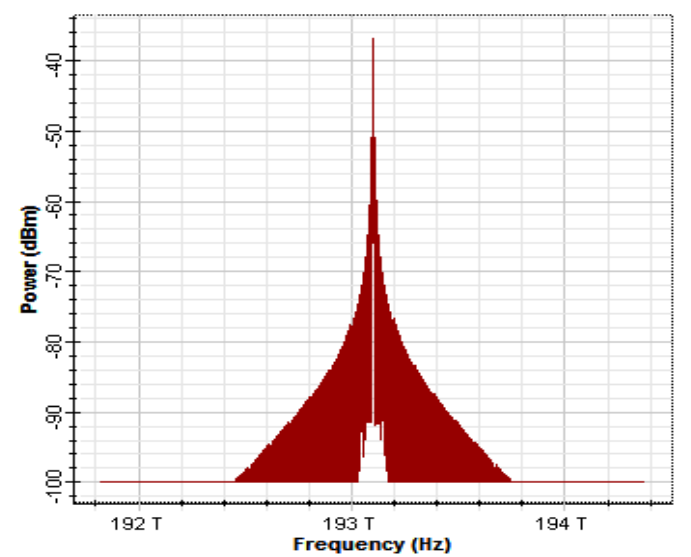

Figure 10. Optical Spectrum of upstream OOK.

\section{를 Optical Spectrum Analyzer_3}

Dbl Click On Objects to open properties. Move Objects with Mouse Drag

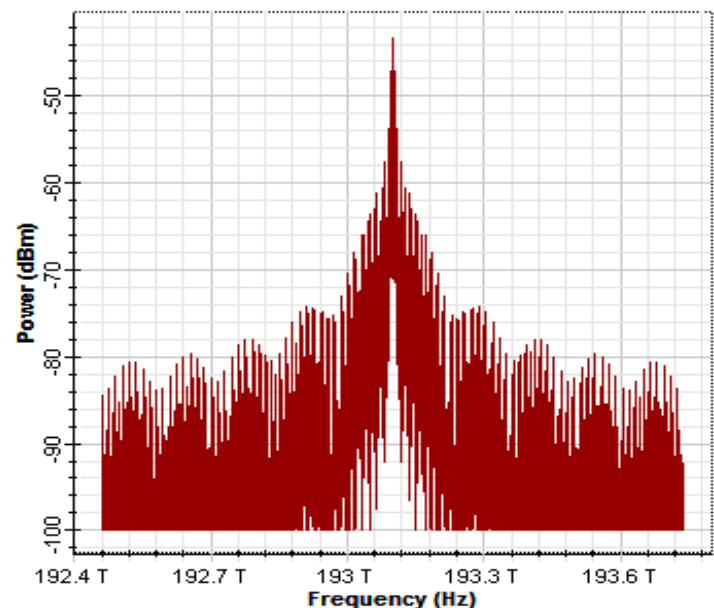

Figure 11. Optical Spectrum of Downstream DQPSK/IRZ. 


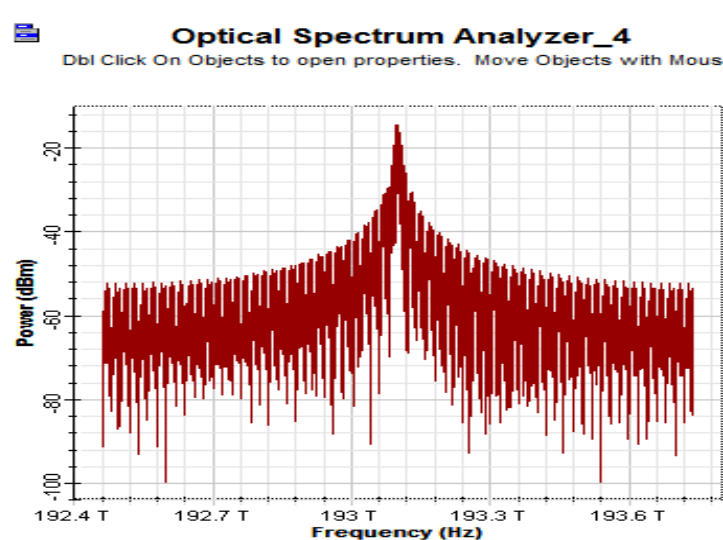

Figure 12. Optical Spectrum of Upstream IRZ.

Figure 13,14,15 and 16 shows the eye diagram of both DQPSK with OOK and DQPSK with IRZ which are wide open having few transmission errors but in an acceptable range to transmit the data. The power and BER of DQPSK/OOK downstream and upstream are $3.41961 \times 10^{-046}$ and $4.10171 \times 10^{-018}$ and $-8.168 \mathrm{~dB}$ and $-34.347 \mathrm{~dB}$ whereas for DQPSK/IRZ are $1.26888 \times 10^{-034}$ and $3.84401 \times 10^{-020}$ and $-8.167 \mathrm{~dB}$ and $-37.824 \mathrm{~dB}$. From the loss margin of both the systems i.e. $-22.832 \mathrm{~dB}$ and $-8.153 \mathrm{~dB}$ for downstream and upstream of DQPSK/OOK and $-34.343 \mathrm{~dB}$ and $-7.676 \mathrm{~dB}$, it can be seen that both systems are feasible for High Data Rate NG-PON 2.

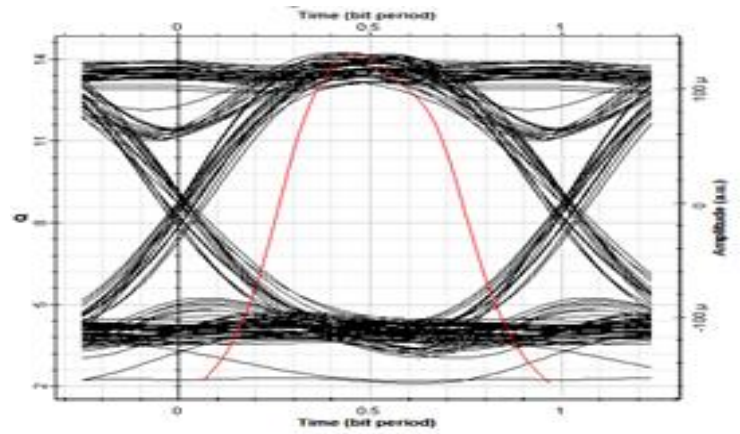

Figure 13. Eye Diagram of Downstream DQPSK with OOK upstream Signal.

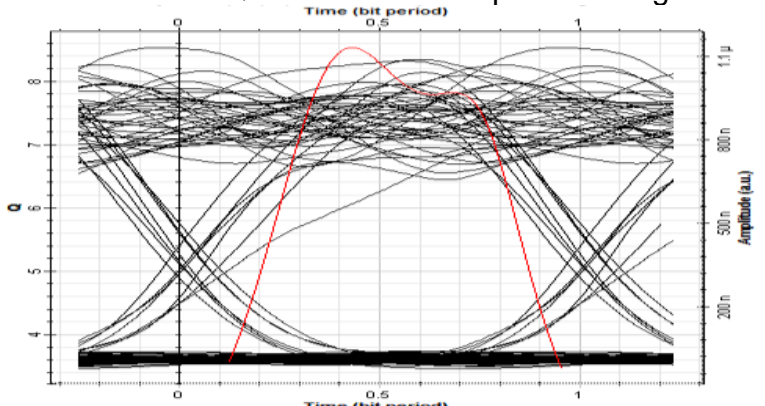

Figure 14. Eye Diagram of Upstream OOK Signal.

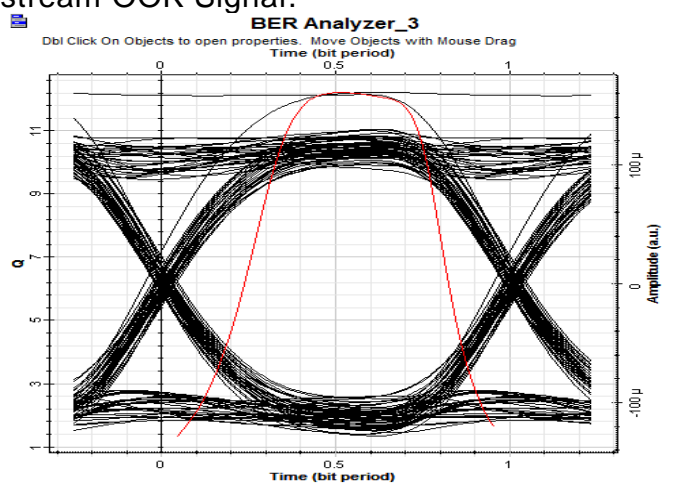

Figure 15. Eye Diagram of Downstream DQPSK with IRZ upstream Signal. 


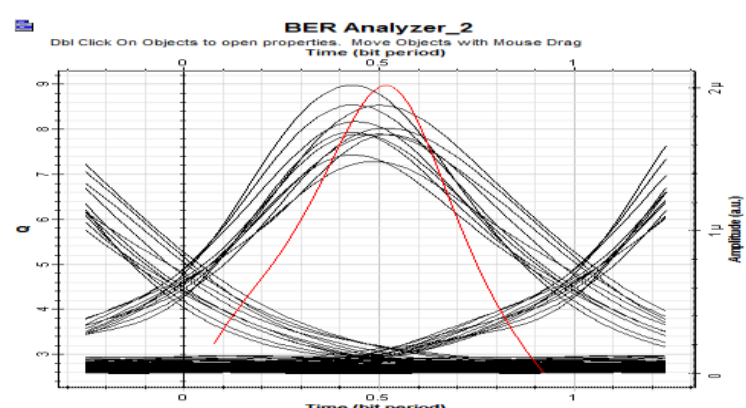

Figure 16. Eye Diagram of Upstream IRZ Signal.

Figure 17 and 18 shows the simulation results obtained on $10 \mathrm{Km}$ and back to back (B2B) fiber span with downstream and upstream of both DQPSK with OOK and DQPSK with IRZ. Figure 17 shows the comparison of downstream of both networks at $10 \mathrm{Km}$ and B2B fiber length. Receiver sensitivity of DQPSK with IRZ at standard BER is much better than DQPSK with OOK on both $10 \mathrm{Km}$ fiber span and B2B i.e. $-31 \mathrm{~dB}$ and $-33 \mathrm{~dB}$ at $10 \mathrm{Km}$ fiber span and $-32 \mathrm{~dB}$ and $-33.5 \mathrm{~dB}$ at B2B. From Figure 17 , it also can be seen that the transmission power penalty of both networks at $10 \mathrm{Km}$ fiber span and $\mathrm{B} 2 \mathrm{~B}$ is $1 \mathrm{~dB}$ and $0.5 \mathrm{~dB}$. Figure 18 shows the comparison of upstream of both networks at $10 \mathrm{Km}$ and $\mathrm{B} 2 \mathrm{~B}$ fiber length. Receiver sensitivity of IRZ at standard BER is much better than OOK on both $10 \mathrm{Km}$ fiber span and B2B i.e. $-38 \mathrm{~dB}$ and $-42.5 \mathrm{~dB}$ at $10 \mathrm{Km}$ fiber span and $-38.5 \mathrm{~dB}$ and $-45.5 \mathrm{~dB}$ at B2B. From Figure 18, it also can be seen that the transmission power penalty of both networks at $10 \mathrm{Km}$ fiber span and $\mathrm{B} 2 \mathrm{~B}$ is $0.5 \mathrm{~dB}$ and $3 \mathrm{~dB}$. Comparison of result is being mentioned in Table 2 .

Table 2. Transmission Performance of DQSPK modulated downstream with OOK and IRZ modulated upstreams.

\begin{tabular}{|l|c|c|c|c|}
\hline & \multicolumn{2}{|c|}{ DQPSK with OOK } & \multicolumn{2}{c|}{ DQPSK with IRZ } \\
\hline Parameters & Downstream & Upstream & Downstream & Upstream \\
\hline Fiber Length & $10 \mathrm{Km}$ & $10 \mathrm{Km}$ & $10 \mathrm{Km}$ & $10 \mathrm{Km}$ \\
\hline Rx Power & $-8.168 \mathrm{~dB}$ & $-34.981 \mathrm{~dB}$ & $-8.167 \mathrm{~dB}$ & $-37.82 \mathrm{~dB}$ \\
\hline Bit Error Rate (BER) & $3.42 \mathrm{e}-46$ & $4.10 \mathrm{e}-18$ & $1.27 \mathrm{e}-34$ & $3.84 \mathrm{e}-20$ \\
\hline $\begin{array}{l}\text { Receiver Sensitivity } \\
\text { @ 1x10 }\end{array}$ & $-31 \mathrm{~dB}$ & $-38 \mathrm{~dB}$ & $-33 \mathrm{~dB}$ & $-42.5 \mathrm{~dB}$ \\
\hline $\begin{array}{l}\text { Optical Signal to } \\
\text { Noise Ratio (OSNR) }\end{array}$ & $8.52 \mathrm{e} 001$ & $6.47 \mathrm{e} 001$ & $8.68 \mathrm{e} 001$ & $6.03 \mathrm{e} 001$ \\
\hline $\begin{array}{l}\text { Txion Power Penalty } \\
\text { B2B vs 10Km }\end{array}$ & $1 \mathrm{~dB}$ & $0.5 \mathrm{~dB}$ & $0.5 \mathrm{~dB}$ & $3 \mathrm{~dB}$ \\
\hline
\end{tabular}


Figure 17. Rx Power vs BER.
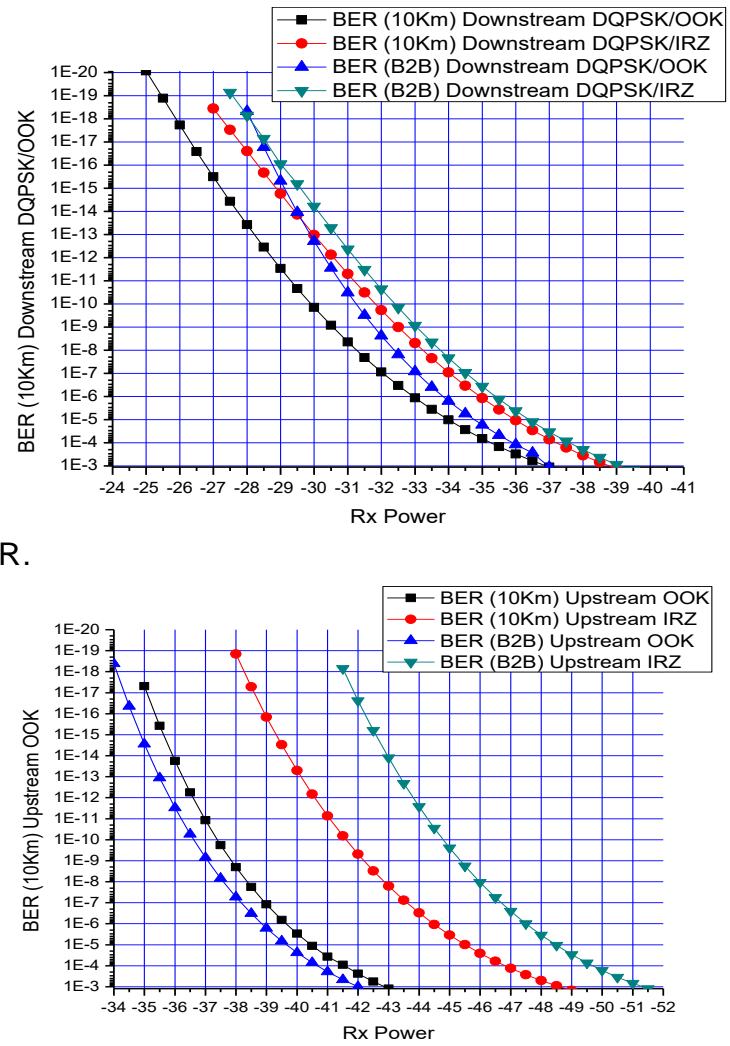

Figure 18. Rx Power vs BER.

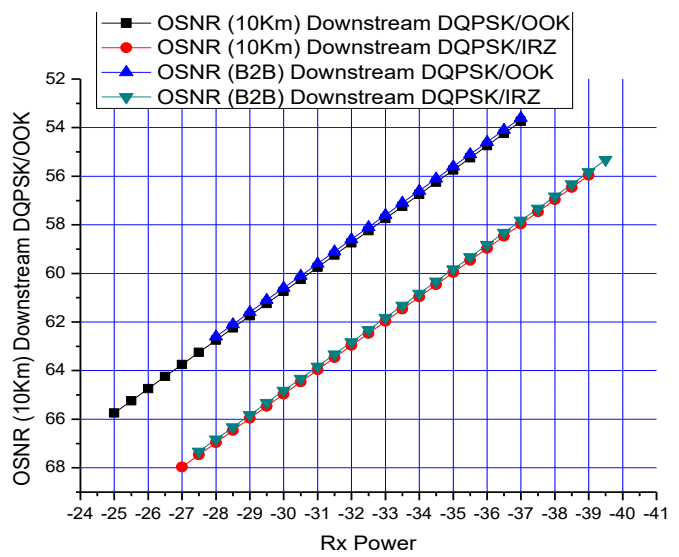

Figure 19. Rx Power vs OSNR.

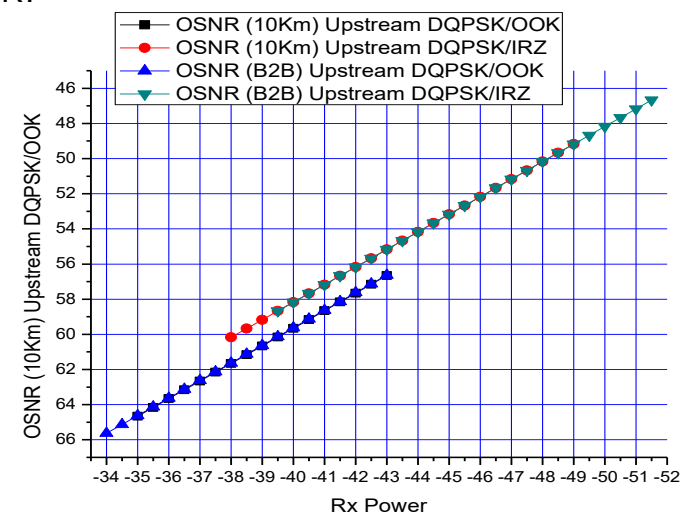

Figure 20. Rx Power vs OSNR.

Figure 19 and 20 shows the simulation results obtained on $10 \mathrm{Km}$ and back to back (B2B) fiber span with downstream and upstream of both DQPSK with OOK and DQPSK with IRZ. Figure 19 shows the comparison of Rx Power vs OSNR at downstream of both 
networks at $10 \mathrm{Km}$ and $\mathrm{B} 2 \mathrm{~B}$ fiber length. It can be seen that as the receiver sensitivity is increased so does OSNR increased. Transmission performance of DQPSK with IRZ at downstream is better compared to DQPSK with OOK as it works at higher receiver sensitivity and OSNR. Figure 20 shows the comparison of Rx power vs OSNR at upstream of both networks at $10 \mathrm{Km}$ and B2B fiber length. Here, it can also be seen that IRZ works at higher receiver sensitivity and high OSNR compared to OOK.

From the results, it can be seen that DQPSK with IRZ network is much better than DQPSK with OOK network in terms of performance as receiver sensitivity is high and transmission power penalty is within the standard range.

\section{CONCLUSIONS}

In this paper, we have investigated two high data rate next generation passive optical network 2 (NG-PON 2) with the same modulation DQPSK at downstream but different modulation formats at upstream i.e. one is OOK and another one is IRZ at $10 \mathrm{Km}$ fiber span. Simulated results validate that transmission performance of DQPSK with IRZ is better than DQPSK with OOK in term of higher receiver sensitivity and better OSNR values with very low transmission power penalties in both directions under the similar simulative conditions.

\section{REFERENCES}

[1] Nesset, Derek. (2017), PON Roadmap [Invited]. Journal of Optical Communications and Networking 9.1. A71-A76

[2] Abbas, H. S., \& Gregory, M. A. (2016). The next generation of passive optical networks: A review. Journal of Network and Computer Applications, 67, 53-74.

[3] Cisco Visual Networking Index: Forecast and Methodology, 2016-2021, June 2, 2017. Accessed on 15 June, 2017

[4] Wei, J. L., Grobe, K., \& Griesser, H. (2016, August). High speed next generation passive optical networks: performance, cost, and power dissipation. In Progress in Electromagnetic Research Symposium (PIERS) (pp. 4856-4857). IEEE.

[5] Nesset, D. (2015). NG-PON2 technology and standards. Journal of Lightwave Technology, 33(5), 1136-1143.

[6] Nakamura, H. (2013, March). Ng-pon2 technology. In National Fiber Optic Engineers Conference (pp. NTh4F-5). Optical Society of America.

[7] Tokle, T., Serbay, M., Jensen, J. B., Rosenkranz, W., \& Jeppesen, P. (2008, February). Advanced modulation formats for transmission systems. In Optical Fiber communication/National Fiber Optic Engineers Conference, 2008. OFC/NFOEC 2008. Conference on (pp. 1-3). IEEE.

[8] Rashed, A. N. Z., Mohamed, A. E. N. A., Tabbour, M. S., \& Ismail, A. M. (2017). Performance Improvement for $16 \times 40 \mathrm{~Gb} / \mathrm{s}$ DWDM System Using Non Return to Zero (NRZ), Return-to Zero (RZ) and Modified Duo Binary RZ (MD-RZ) Modulation Formats. International Journal of Advanced Research in Computer Science and Electronics Engineering (IJARCSEE), 6(2), pp-11.

[9] Kamalpreet. Miss Bhawna Utreja May (2015). Performance Analysis of CSRZ, MDRZ, NRZ and DPSK Modulation Formats for Two Channel WDM Passive Optical Network. International Journal of Engineering and Applied Sciences (IJEAS) ISSN: 2394-3661, 
Volume-2, Issue-5 at https://www.ijeas.org/download data/IJEAS0205047.pdf. PDF file.

[10] Garg, A. K., \& Janyani, V. (2015). Analysis of OOK Upstream Signal Remodulation for Different Data Rates in WDM PON Network.

[11] Islam, T. U., Hussain, A., \& Ashraf, S. S. (2015, December). 10Gbps bidirectional transmission GPON network based on single fiber. In Emerging Technologies (ICET), 2015 International Conference on (pp. 1-4). IEEE.

[12] Latal, J., Vitasek, J., Koudelka, P., Siska, P., Poboril, R., Hajek, L., \& Vasinek, V. (2014, July). Simulation of modulation formats for optical access network based on WDMPON. In Transparent Optical Networks (ICTON), 2014 16th International Conference on (pp. 1-7). IEEE.

[13] Chenika, A., Temmar, A., \& Seddiki, O. (2014). Transmission of $4 \times 40 / 10 \mathrm{Gbps}$ in a WDM-PON using NRZ-DQPSK/ASK modulation. Optik-International Journal for Light and Electron Optics, 125(20), 6296-6298.

[14] Chenika, A., Temmar, A., \& Seddiki, O. (2013). A Novel architecture of an optical highspeed access network WDM-PON using NRZ-DQPSK/ASK modulation. ICNCRE'13, ISBN: 978-81-925233-S-5, 1, 396-398.

[15] Khan, A. M., Zhang, J., Zhao, Y., Khan, Y., Latif, A., \& Han, J. (2013). A Cost-effective and Spectrally-efficient Design of Centralized Light Source WDM-PON using Aggregated 160 Gbit/s DQPSK Modulation for Downstream and Re-modulated IRZ for Upstream Transmission. Advances in Information Sciences and Service Sciences, 5(3), 305.

[16] Khan, A. M., Jie, Z., Khan, Y., Idrees, M., Zhao, Y., Niazi, S., \& Liu, J. (2013). A Simple and Cost-effective Design for Simultaneous Transmission of Point-to-point and Broadcast Services in WDM-PON. International Journal of Future Generation Communication and Networking, 6(3), 41-56.

[17] Memon, A. K., Khan, A. M., Musavi, S. H. A., \& Gaho, A. A. (2017). Viable Solution for Next Generation Passive Optical Network 2 (NG-PON 2) Supporting 40Gbps Downstream DQPSK and 10Gbps Upstream OOK. INTERNATIONAL JOURNAL OF FUTURE GENERATION COMMUNICATION AND NETWORKING, 10(8), 29-37.

[18] Das, B., Mukherjee, R., Mandal, G. C., \& Patra, A. S. 40 Gbps Downstream Transmission Using DQPSK and 20 Gbps Upstream Transmission Using IRZ Modulation in FullDuplex WDM-PON. Journal of Optical Communications.

[19] Li, L., Zhang, J., Duan, D., \& Yin, A. (2012). Analysis modulation formats of DQPSK in WDM-PON system. Optik-International Journal for Light and Electron Optics, 123(22), 2050-2055.

[20] YUAN, X. G., ZHANG, J. N., ZHANG, Y. A., ZHANG, M. L., HUANG, Y. Q., \& REN, X. M. (2010). Experimental demonstration and analysis of all-optical label swapping based on RZ-DQPSK/IRZ-ASK modulation format. The Journal of China Universities of Posts and Telecommunications, 17(1), 101-105.

[21] El-Nahal, F. I. (2017). A WDM-PON with DPSK modulated downstream and OOK modulated upstream signals based on symmetric $10 \mathrm{Gbit} / \mathrm{s}$ wavelength reused bidirectional reflective SOA. Optoelectronics Letters, 13(1), 67-69.

[22] https://optiwave.com/ 


\section{AUTHORS}

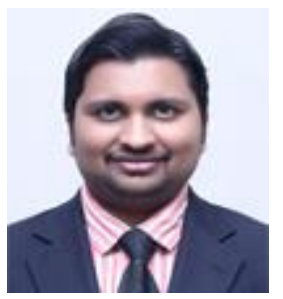

Areez Khalil Memon, He has done B.E(Electronics) from Mehran University of Engineering and Technology, Jamshoro, Sindh, Pakistan (Jan, 2006 - March, 2010) and Masters From University of Leicester, United Kingdom (UK) in MSc Advanced Electrical and Electronics Engineering. Currently, he is doing $\mathrm{PhD}$ in Electrical Engineering from Indus University, Karachi. He has 15 research publications in conferences, IEEE proceedings and journal. A part from his teaching and research activities he is also a member of Board of Studies and Board of Faculty in Indus University. He has good knowledge of Renewable Energy, Electrical Machines, Control Engineering and Passive Optical Networks. His core research areas are Next Generation Passive Optical Network 2 (NG-PON 2) and Energy efficient NG-PON 2.

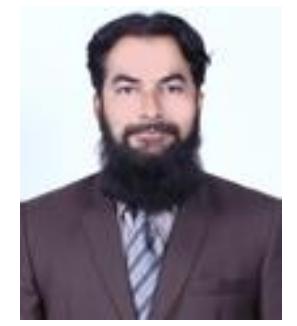

Ahmed Muddassir Khan, he has completed his early education from prestigious institutes of Pakistan with distinctions. He completed B.E. (Electronics) from Mehran University Jamshoro, M.Engg. (Telecommunication) from NED University, Karachi and MBA from Federal Urdu University, Karachi. He started his professional career as a Telecom Engineer in Pakistan's leading Telecom organization (PTCL) and gained vast field and research experience in high capacity optical networks. Then he started PhD from Beijing University of Posts and Telecommunication (BUPT), Beijing, China. His research based on implementation of Robust Advanced Modulation Formats for Cost effective and High capacity Next Generation Passive Optical networks $(\mathrm{PON})$. He has completed $\mathrm{PhD}$ with several research publications in esteemed international research journals. Currently, he is working in Indus University, Karachi, as an Associate Professor and Chairperson of Department of Electrical Engineering in Faculty of Engineering, Science and Technology (FEST). He also has other important academic role and responsibilities in Indus University such as Chair of BOS, member of BOF, Academic Council, and R\&D Committee. He is an approved PhD supervisor and selected as an NTC Program evaluator by higher education commission (HEC), Pakistan. He is also member of different national and internal societies and speaker in different research forums. He served as an organizing committee and technical Co-chair in IEEE ICIEECT 2017. He also has successfully supervised ICT R\&D funded projects His core research areas are Optical Communication, DWDM, GPON, Hybrid WDM/TDM-PON, Submarine Optical Fiber Cable Networks, Advanced Modulation Formats and Next Generation Passive Optical Networks (NGPON). 


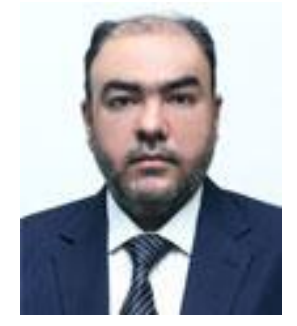

Sayed Hyder Abbas Musavi, He is $\mathrm{PhD}$ and $\mathrm{ME}$ in Telecommunication Engineering under HEC Scholarship and B.E. in Electronics Engineering from Mehran University of Engineering and Technology, Pakistan. He is currently serving as Dean Faculty of Engineering Science and Technology Indus University Karachi. Previously he was engaged as Chairman Department of Electrical and Electronics Engineering Hamdard University Karachi. In past he has served as Professor and Principal at Petroman- an Institute of Ministry of Information Technology and Telecommunications, Government of Pakistan at its various campuses for more than 10 years and had also remained Executive District Officer IT (EDO-IT) District Government Larkana. To his credit are more than 30 research publications in national and international journals. Dr. Musavi has attended numerous international conferences as invited speaker. He is on review board of two impact factor international journals. He is member of numerous national and international societies including member IEEEP Karachi local council, IEEE, IEEE Computer society, IEEE Signal Processing Society, IEEE Devices and Circuits Society, IEEE Communications Society etc. He was General Chair in IEEE ICIEECT 2017.

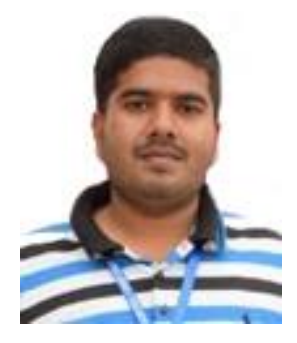

Faizan ur Rehman, Computer Systems Engineer from COMSATS Institute of Information Technology (CIIT) Wah Cantt and Masters in Electrical Engineering from National University of Computer and Emerging Science (NUCES-FAST) Lahore. He is currently working at Indus University Karachi as a Lecturer. His areas of research are Next Generation Passive Optical Networks and Speaker Recognition System.

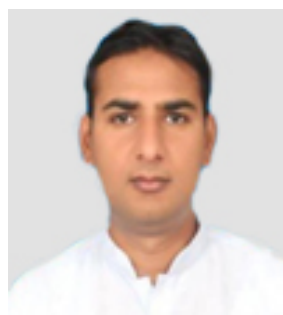

Engr. Atif Mehmood has completed his Bachelor of Computer Engineering from COMSATS IIT Wah cantt and Master in Electrical Engineering from FAST (National University of computer and Emerging Sciences). He joined Commtel System as Field Incharge Engineer and works on HEC Smart University Project in different universities in 2016. He also completed multiple projects in different industries like Bestway Cement, Pakistan Tobacco Company, Askari Cement, Cherat Cement, English Biscuit Manufacturer, Nishat Paper Mill. His areas of research are Next Generation Passive Optical Networks and Parallel Synchronization of Grid Stations.

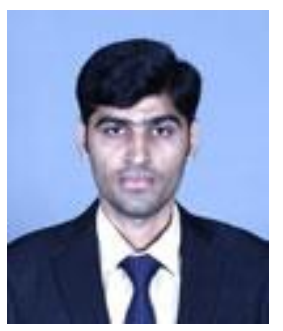

Engr. Sajid Hussain is PEC Certified Engineer with B.E in Electronics. Currently doing M.Engg in Industrial Electronics. Has working experience of around 3 years in different industries. His areas of research are Next Generation Passive Optical Networks. 
Simulative investigation of transmission performance for proposed NG PON 2 based on DPQSK modulated downstream with two diferent intensity modulated upstreams DOI: http://dx.doi.org/10.17993/3ctecno.2019.specialissue.11 